\title{
Política de estado: INCLUSIÓN, IGUALDAD Y DESARROLLO SOCIAL (State policy: inclusion, equality and social development)
}

\section{Entrevista a:}

Dr. Luis Felipe Henao Cardona

Ministro de Vivienda

Abogado de la Universidad del Rosario

Especialista en Derecho de la Empresa de la Universidad del Rosario

Especialista en Estudios Superiores en Problemas actuales del Derecho Penal de la Universidad de Salamanca (España)

Candidato a Doctor en Derecho Penal en la Universidad de Salamanca (España)

Docente destacado en los programas de pregrado y posgrado de la especialización de Derecho Penal y del Diplomado Derecho Penal Económico de la Universidad del Rosario.

Profesor del Diplomado de Derecho Disciplinario en la Universidad de Medellín.

¿Cuáles considera usted que son los factores que han determinado el problema de la desigualdad en Colombia?

...Pues, la desigualdad en Colombia, hay temas que determinan que se aumente o se disminuya; sin lugar a dudas, los factores que han generado un mayor número de desigualdad es el acceso a la educación, creo que es uno de los temas más importantes, acceso a los servicios públicos, acceso al trabajo, acceso a la formación infantil y acceso a la vivienda. Pueden haber muchos factores para determinar si una persona está en pobreza 0 no, pero hay unos factores que nos determinan cómo hacemos para que una persona tenga mayor oportunidad de desarrollarse en sociedad; entonces, hay que darle herramientas. La democracia en sí es poder darle herramientas a una persona, seas tú, sea yo, sea Paula, para que se pueda desarrollar en sociedad, y esas herramientas, por muchos años en Colombia, han estado restringidas y por eso la desigualdad en Colombia es una desigualdad importante. Nosotros encontramos este país, o más que nosotros el presidente Santos, encontró este país con una medalla que uno no quisiera cargar: ser el segundo país más desigual de América Latina; o sea, estábamos debajo de Haití, que era el primero. Hoy, después de cinco años de gobierno, todavía nos falta por avanzar mucho, pero ya no estamos en ese segundo lugar, y eso se debe a que se han tomado políticas donde los temas en que más hemos avanzado y donde tal vez somos el país de Latinoamérica donde más hemos avanzado, es la reducción de la pobreza; por eso, ya se han sacado cuatro millones cuatrocientos mil colombianos de la pobreza.
En ese sentido, iqué acciones políticas y económicas se han dado en Colombia en los últimos cinco años para la superación de la pobreza y de la pobreza extrema en el país?

Primero, los indicadores hablan por sí solos, pues hemos logrado sacar cuatro millones cuatrocientos mil colombianos de la pobreza. Hemos logrado bajar la tasa de pobreza a $28,1 \%$ y hemos logrado también disminuir la pobreza extrema con una consecuencia importante que es el aumento de la clase media; ieso a que se debe?: primero, a que hemos tenido una política económica, que es una política económica del Estado, con un crecimiento superior al 4,5 \%; ya te voy a explicar este tema económico, porque... y ahorita que tenemos la coyuntura de los comodines, que es todo lo que tiene que ver con petróleo, todo lo que tiene que ver con carbón, Colombia, aunque somos un país que depende de forma importante de esos sectores, hemos tenido una política económica ortodoxa que ha hecho que hubiéramos sido, por ejemplo en este primer trimestre, el país que más creció en Latinoamérica; ieso a que conlleva?: a que la receta más importante para poder superar la pobreza es poder tener empleo y tener crecimiento económico.Styleseñalaba, en el tema de desigualdad, que tal vez el PIB para las personas es indiferente; el PIB hay que aterrizarlo a que las personas tengan empleo, a que las personas puedan tener, a través de ese empleo, accesibilidad a ciertos bienes y servicios. Y Colombia ha sido el país que en estos cinco años, hemos podido bajar cada mes consecutivo el indicador de desempleo; además, a eso se le unen unas serie de políticas importantes, políticas como la política 
de educación, como la política "De cero a siempre" para los niños, políticas como la de "Ser pilo paga". Y todo lo que se va a hacer en materia de educación es importante, dando pasos muy importantes, por ejemplo, en universalidad de la educación, donde en este Gobierno la educación es universal. Ahorita estaba mirando una encuesta y mucha gente que no quiere estudiar, es porque no quiere estudiar; pero, por primera vez, tenemos un presupuesto más alto que para la guerra.

Otro tema importante es la universalización en materia de salud, que aunque nosotros nos quejemos todos los días, es tal vez el avance más importante desde que tenemos la Constitución del 9l: el avance en salud. Somos el país en Latinoamérica que menos paga gasto de bolsillo en materia de salud; o sea, la gente se puede quejar que la EPS es demorada, pero cuando uno mira cuánto sale del bolsillo del Gobierno y cuánto sale del bolsillo del paciente, somos el país en Latinoamérica con menos gasto de salud $y$, tal vez, el país que más tiene incluidos tratamientos.

En materia de vivienda logramos algo fundamental: el país construía más vivienda para estratos medios y altos que para estratos bajos en el anterior Gobierno, en el cual yo también fui viceministro; por eso, no lo hago como una crítica, sino como una autocrítica. El país construyó de 2006 a 2010, quinientas cuarenta mil viviendas, que era el punto más alto de construcción; de esas quinientas cuarenta mil, más del $60 \%$, eran viviendas diferentes a interés social; o sea, era vivienda para estrato medio y alto. Nosotros, en este Gobierno del cual yo hago parte, primero como viceministro y ahorita como ministro, hemos construido, en cinco años, un millón ochenta mil viviendas; o sea, casi el doble de lo que se construyó en el Gobierno pasado, pero con un sello de calidad; ese sello de calidad fue que se construyó más vivienda de interés social que otro tipo de vivienda; eso significa que hubo mayor accesibilidad de las personas porque tuvieron un subsidio o porque tuvieron una tasa mucho más baja a la política de vivienda.

En materia de servicios públicos, ya en áreas urbanas tenemos una cobertura del $97 \%$. Nos falta avanzar en las áreas rurales, y las coberturas que ha hecho el ministro Tomás en materia de energía, son coberturas enormes; entonces, el tema de luz a mejorado mucho. Lo que hay que mejorar es la calidad del servicio en algunos sectores; por ejemplo, la costa con Electrocaribe; pero en servicios públicos también se ha avanzado. Yo creo que todo eso está ayudando a que por primera vez estemos disminuyendo la desigualdad: aumentando el número de personas que están saliendo de la pobreza para tener un país con mayor clase media.

¿Cuáles considera usted que son las características principales de una sociedad incluyente y progresista?, y ¿cómo lograr esto en Colombia?

Lo que te decía, tener más educación, más acceso a servicios públicos, mejor calidad de salud y lo que estamos desarrollando nosotros a través de la Vicepresidencia, con liderazgo del Presidente, es el desatraso en materia de conectividad: todo lo que se está haciendo en 4G. Tal vez la obra más importante en infraestructura que la gente tiene en la cabeza en Latinoamérica es el Canal de Panamá; nosotros estamos haciendo tres veces lo del Canal de Panamá: poder hacer las cuatro $G$, poder pasar de ranking 18 a ranking número 3 en materia de infraestructura por todo lo que se va a hacer por materia fluvial, todo el tema del río Magdalena, todo lo que se va a hacer en materia urbana, la primera ola, la segunda ola de vías de cuarta generación, todo lo que se va hacer en vía férrea, la intervención a los cincuenta y dos aeropuertos, va a generar algo, y es que por donde pasan esas vías, por donde pasen, en esos municipios, van a generar desarrollo y eso va a desentrañar mucho la desigualdad que hay entre ciertas regiones del país.

¿Qué papel cree usted que cumplen las instituciones estatales en la construcción de comunidades incluyentes?

Pues toda; toda, y no solamente es la vinculación de la sociedad civil con políticas estatales: todo lo que está haciendo el Departamento de Prosperidad es fundamental para generar conexión social; todo lo que está haciendo el Instituto de Bienestar Familiar, todo lo que está haciendo el Sena, todo lo que hace la sociedad civil a través de instituciones tan importantes como la Universidad Minuto de Dios, son procesos de generar oportunidades a personas que antes no podían aspirar a la educación superior y que ahora están pudiendo aspirar, y gracias a eso salen del circulo vicioso de la pobreza. Uno tiene que buscar vencer ese círculo que genera la pobreza: de que mi papá fue pobre, yo soy pobre y mi hijo va hacer pobre. La única forma de salir de ese círculo de la pobreza es dar herramientas para que las personas salgan; entonces, por ejemplo, lo que ustedes hacen a través de la Universidad Minuto de Dios, lo que se está haciendo a través del SENA para tener más personas con tecnología, lo que se está haciendo a través de ICBF para tener la posibilidad de tener más personas con atención infantil, eso es fundamental. 
¿Cuáles considera usted que son los logros que ha tenido el Ministerio de Vivienda frente a las necesidades socioeconómicas de la población colombiana?

Primero, una mayor accesibilidad a la política de vivienda. Logramos, por primera vez, entender que la política de vivienda es una política que se tiene que desarrollar de forma muy integral. ¿Eso qué significa, Félix?: que hay que entender que tú eres diferente a Paula, y que Paula es diferente a mí, y que tal vez tú tienes una necesidad diferente, Paula tiene una necesidad diferente; por eso, para las personas más vulnerables desarrollamos el programa de "Vivienda gratuita"; para las personas que ganan entre uno y dos salarios mínimos desarrollamos el programa de "Casa ahorro". Es fundamental para una persona de un salario mínimo que se gastaba cuatrocientos mil en un arrendamiento; es fundamental que pueda comprar su vivienda desde ciento ochenta mil pesos.

Style decía: "Una política no es solamente decir un discurso, una política es transferirle efectivamente un beneficio a una persona"; y transferirle no es darle plata; transferirle es que tú puedas tener un colegio más cercano, un punto de salud mucho más cercano o gastarte menos en un arrendamiento comprando un bien o servicio para tu calidad de vida. A una persona no hay que subirle el salario mínimo, por ejemplo en este caso, para que puedas percibir mayores ingresos. Si yo me gastaba cuatrocientos mil pesos en un arrendamiento, y ya me estoy gastando ciento ochenta mil pesos en mi propia vivienda, quiere decir que tengo un ahorro de doscientos veinte mil pesos; esos doscientos veinte mil pesos, que siguen siendo escasos, te pueden permitir mejor alimentación, te pueden permitir mejor educación, con herramientas textos o algo; te pueden permitir tener mejor calidad de vida.

Y para las personas que ganan entre dos y cuatro salarios mínimos, desarrollamos el programa, "Mi casa ya", que también es fundamental. Ayer estuvimos entregando viviendas en Bello. Una niña me decía: "Yo gastaba más en arriendo, que lo que me estoy gastando ahorita". Personas de ingresos, una niña que se ganaba millón doscientos mil pesos, gastaba cuatrocientos ochenta mil pesos en un arriendo; ahorita está comprando su propia casa desde cuatrocientos treinta mil pesos.

Y para las personas que tienen mayores ingresos, desarrollamos el programa de vivienda, "Subsidio a la tasa de interés", donde financiamos el $30 \%$ del tema. Pero, también, desde el Ministerio estamos desarrollando una política de acompañamiento a las ciudades para que tengan mejor espacio público: si hay mejor espacio público existe una democratización a la mejor calidad de vida, para que sepan dónde invertir en forma mejor y a eso también le estamos apostando.

¿De qué manera podría el Ministerio de Vivienda articularse al Sistema Nacional de Ciencia Tecnología e Innovación de Colciencias para lograr adelantar proyectos orientados al mejoramiento del nivel y la calidad de vida de la población colombiana?

Bueno, nosotros ya estamos vinculados; por ejemplo, en todo el tema de Colciencias se están privilegiando los proyectos de desarrollo de las ciudades, a través de sistemas tan importantes como planear bien las ciudades. Entonces, para Montería queremos desarrollar La Acrópolis. Montería tiene una vocación inminentemente agropecuaria y hay que desarrollar todas las herramientas para que una persona allá pueda exportar sus productos, vender sus productos; ese es un proyecto que se le llevó, por ejemplo, a través de Findeter a Colciencias, en nuevas tecnologías para desarrollar, nuevas tecnologías en materia de vivienda. También hemos tenido vinculación con Colciencias. Entonces, todo ese desarrollo, toda esa ingeniería, donde uno por ejemplo tiene que saber cuáles son las potencialidades de cada región, la estamos desarrollando con proyectos que, en muchos casos, nos está desarrollando Colciencias a través del rango de regalías, donde un porcentaje de regalías se tienen que invertir en innovación, por ejemplo.

¿Cuál cree usted que es el papel de la academia y de los investigadores en la construcción de un país más equitativo?

El papel de la academia es eso. Yo creo que hay que pensar en mejores ciudades, mejor desarrollo urbano. La academia es la que tiene que alertar cuando existan riesgos, por ejemplo en la prestación de servicios básicos: riesgos de agua, riesgos de energía, riesgos de segregación por determinadas políticas. Entonces, la academia es fundamental en cada una de esas decisiones y tiene que ser un permanente consultor de las decisiones que tome el funcionario público.

Por último, la Corporación Universitaria Minuto de Dios -UNIMINUTO pretende, desde su misión, una "educación de calidad al alcance de todos"; ien qué beneficia este aporte a la propuesta inclusiva del Gobierno nacional?

En lo que te decía en toda la entrevista, si existen profesionales que tengan la oportunidad, si existe una 
persona que antes no tenía acceso a la educación y, gracias a UNIMINUTO, esa persona tiene mayor oportunidad de desarrollarse en una sociedad, puede ser un arquitecto que nos sirva para algún proyecto nuestro, puede ser un ingeniero, puede ser un abogado, y eso para un país es cortar el círculo vicioso de la pobreza. La herramienta más importante para sacar una persona de la pobreza, sin lugar a dudas, es la educación: es la inversión que mayor rendimiento tiene en la sociedad; si tú inviertes un peso en la educación, estás sacando diez pesos de la economía \& 